\title{
Polyimide/silica hybrids via the sol-gel route: High performance materials for the new technological challenges
}

\author{
G. Ragosta*, P. Musto
}

National Research Council of Italy, Institute of Chemistry and Technology of Polymers (ICTP), Via Campi Flegrei 34, Olivetti Buildings, 80078 Pozzuoli, NA, Italy

Received 24 February 2009; accepted in revised form 16 April 2009

\begin{abstract}
The present review article describes in detail the state-of-the-art of organic-inorganic hybrid materials based on polyimide/silica components. The article is divided in three parts. In the first the basic processing route for the preparation of these systems is described, i.e. the sol-gel technique, along with the strategies developed to control the final morphology. In the second part the curing characteristics, the dynamic-mechanical and the mechanical and fracture properties of hybrids with different morphologies are reviewed. Finally, the more technologically relevant applications devised for these high performance materials are discussed.
\end{abstract}

Keywords: nanocomposites, hybrid materials, polyimide, silica, sol-gel

\section{Introduction}

Polyimides (PI) are a class of high-performance polymers possessing the cyclic imide and aromatic groups in the main chains. The most familiar polyimide is widely known as Kapton, developed by $\mathrm{Du}$ Pont in the 1960s. After the marketing of this polyimide, many others were commercially developed with some modified properties. They have gained considerable importance in advanced areas such as microelectronics, aerospace and separation technologies owing to their outstanding properties in terms of thermal stability, mechanical properties, and solvent resistance, coupled with relatively low permittivity and dielectric losses up to very high temperatures [1-3]. In order to facilitate progress of PIs in their application fields, much effort has been spent to further improve their properties. This can been achieved through the formation of in situ gen-

*Corresponding author, e-mail: rago@ictp.cnr.it (C) BME-PT erated inorganic particles to produce organic-inorganic $(\mathrm{O} / \mathrm{I})$ hybrid materials [4-7].

The O/I systems have been recognized as a new class of high performance materials owing to the unique opportunity that these systems provide to combine the excellent properties of inorganic glasses, such as high modulus, thermal stability and low coefficient of thermal expansion, with the ductility and low temperature processing characteristics of organic polymers. When the two phases are interconnected and the domain sizes of these phases approach those of supramolecular entities, these materials are known as nanostructured materials or 'phase-interconnected' nanocomposites [8-11].

Hybrid materials offer a large potential for applications in a variety of advanced technologies, either as structural materials [6], including their use as matrices for high performance composites [12, 13], 
or as functional materials [14] such as catalyst supports [15] and microelectronic devices [16]. The sol-gel route represents the preferred way for the synthesis of polyimide based hybrids. The classical sol-gel process consists in a two step hydrolysis-condensation reaction, starting with a metal alkoxides $\mathrm{M}(\mathrm{OR})_{4}$, typically tetraethoxisilane $\mathrm{Si}\left(\mathrm{OCH}_{2} \mathrm{CH}_{3}\right)_{4}$ or titanium isopropoxide $\mathrm{Ti}\left[\mathrm{OCH}\left(\mathrm{CH}_{3}\right)_{2}\right]_{4}$, to produce hydroxyl groups followed by the polycondensation of the hydroxyl groups and residual alkoxy groups to form a three-dimensional network [5, 17-21].

Polyimides are particularly suited for this type of process because they can be obtained from polyamic acid precursors, which are soluble in hygroscopic solvents and can, therefore, tolerate the addition of water necessary to bring about the hydrolysis of the metal alkoxide. Moreover, the outstanding thermal stability of polyimides allows the hybrids to be post-cured at very high temperatures $\left(300-350^{\circ} \mathrm{C}\right)$ making it possible the development of a very dense inorganic network without inducing appreciable degradation of the organic phase.

Polyimide/silica hybrids made by the sol-gel technique are the subject of this review, in which the approaches used for a close control of their final morphology, the effects of the silica phase on the curing process of polyimide precursors, the dynamic-mechanical and the mechanical and fracture properties that these materials can display, and their possible applications will be presented and discussed.

\section{Processing and morphology}

A typical procedure for the preparation of PI/silica hybrids via the sol-gel route, involves the following steps:

i) The polyamic acid (PAA) (PI precursor) is formed by a polyaddition reaction of a dianhydride [e.g., pyromellitic anhydride (PMDA), 3,3',4,4'-biphenyltetracarboxylic dianhydride (BPDA), or 2,2-bis(3,4-dicarboxy-phenyl)-hexafluoropropane dianhydride (6FDA)] with a diamine [e.g., 4,4'-oxydianiline (ODA), or p-phenylen diamine (PPA)] in a common solvent [e.g., dimethylacetamide (DMAc), or $\mathrm{N}$-methyl pyrolidone (NMP)]. The reaction and chemical structures of monomers are reported in Figure 1.

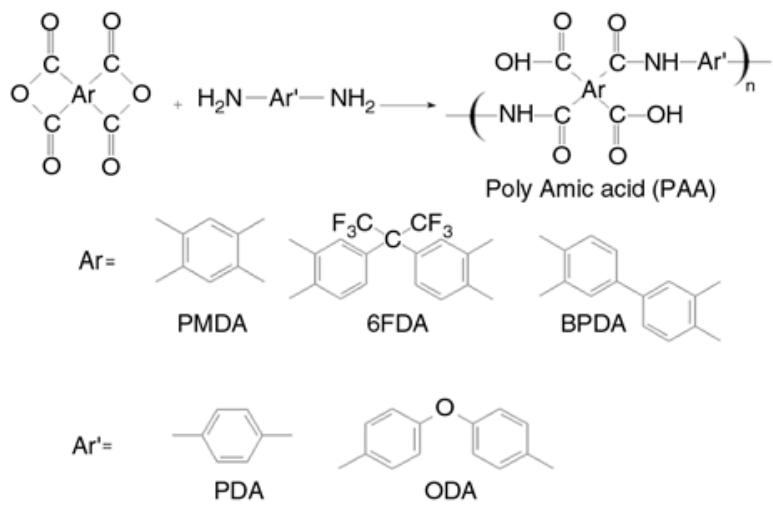

Figure 1. Formation of polyamic acids, the precursor of polyimides

ii) The silica precursor [e.g., tetraethoxysilane (TEOS) or tetramethoxysilane (TMOS) is added to the PAA solution, and the hydrolysis and polycondensation is carried out using an appropriate catalyst.

iii) The PAA/silica solution is film cast by drying the solvent, and then the film is cured by successive heating treatments up to $300^{\circ} \mathrm{C}$. The heating induces the imidization reaction to convert PAA to PI and the crosslinking of the

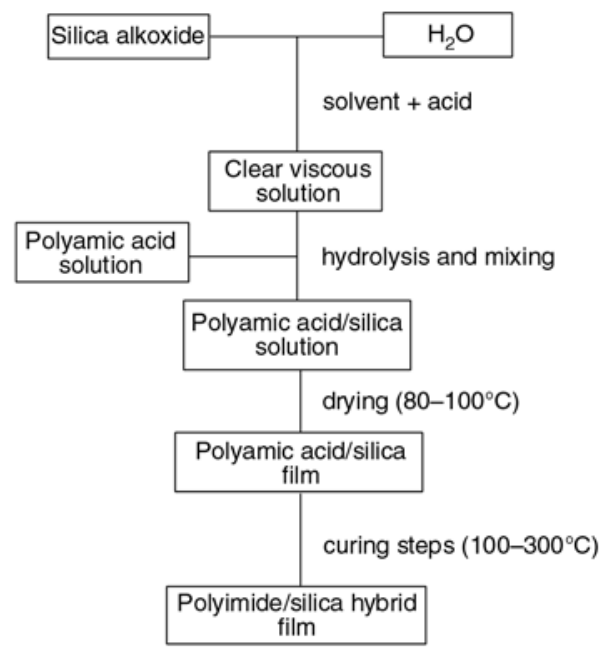

Silanes:

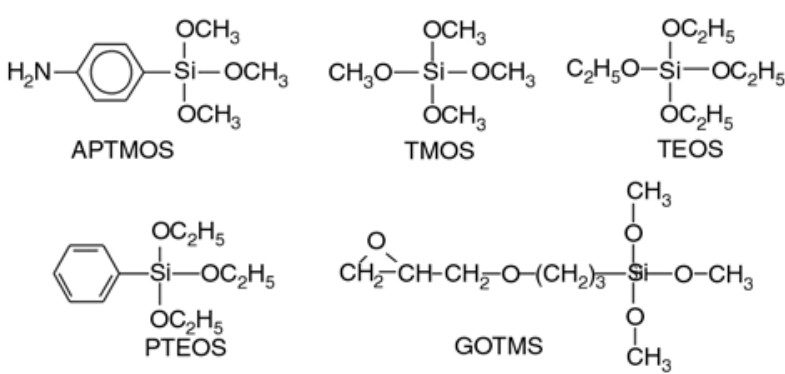

Figure 2. Sol-gel process for the production of a polyimide/silica hybrid and the structures of some alkoxisilanes 
siloxane component to form a silica network. This route is outlined in Figure 2 where the structures of some silanes discussed in the present review are also reported.

The types of reactions involved in the preparation of PI/silica hybrids allow to exert a considerable control on the final morphology by preventing premature phase separation. This is achievable by optimizing the processing parameters (temperature, catalyst and nature of the solvent) and by promoting reactions or interactions between the two components, either directly or via a coupling agent. Various methods for effectively introducing a silica phase into PI matrices have been reported by Nandi et al. [17, 22], Morikawa et al. [7, 11], Wang et al. [23], Mascia et al. [8, 13], Schmidt and Wolter [24, 25] among other. Given below is an account of some of the approaches used.

In earlier studies, large sized silica domains were generated with inhomogeneous distribution within polyimide matrices. This led to brittle materials with poor mechanical properties. In order to minimize the size of the inorganic particles and to prevent their agglomeration, Nandi and co-workers prepared polyimide-silica hybrids via the 'site isolation method' [17, 22]. This method consisted of pre-binding an alkoxide precursor to a polyamic acid, forming a carboxylate group, and subsequently curing the system to imidize the polyamic acid and to drive the sol-gel reactions. Homogeneously dispersed silica particles of nanometer dimensions were observed in the polyimide matrix, particularly at low silica content, although micronsized particles were evident at higher silica concentrations (> $40 \mathrm{wt} \%$ ). However, this approach had the drawback that the prebinding of the alkoxide precursor prevented a complete imidization of the polyamic acid.

Morikawa et al. [7, 26] produced PI/silica hybrids by mixing TEOS solutions and a polyamic acid, obtained from the reaction of PMDA and ODA. Except for systems with low silica content $(<10 \mathrm{wt} \%)$, the films were opaque and contained coarse silica particles 3-7 $\mu \mathrm{m}$ in diameter. In later studies these authors $[11,27]$ greatly improved the morphology and properties of these hybrids by introducing different types and concentrations of pendant alkoxysilanes along the polyimide backbone. These pendant groups provided connection points to the silica particles. The SEM results showed that the silica particle size was $0.5-1.0 \mu \mathrm{m}$, i.e. smaller than those in the previous studies, and the particles were homogeneously distributed. These results were attributed to increased compatibility owing to interactions between the organic and inorganic phases.

Mascia and Kioul [5, 8, 21] and Mascia and coworkers [28, 29], showed that the compatibility in PI/silica hybrids can be greatly improved by adding to TEOS solutions a functional alkoxysilane coupling agent such as $\gamma$-glycidyloxipropyl trimethoxysilane (GOTMS). The SEM micrographs of Figure 3 for PI hybrids with 22.3 wt $\%$ of silica illustrate the compatibilization effect of GOTMS, which brings about a morphological transformation from a dispersed particle microstructure (Figure 3a), in absence of GOTMS to a finely interconnected or co-continuous phase morphology (Figure 3b), with the use of GOTMS [28]. For the compatibilized system the size of the interconnected silica domains ranges from 40 to

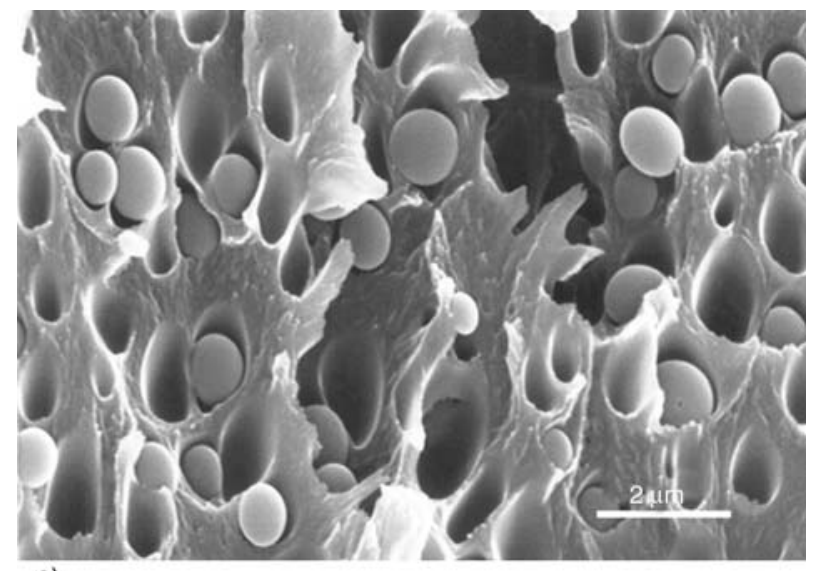

a)

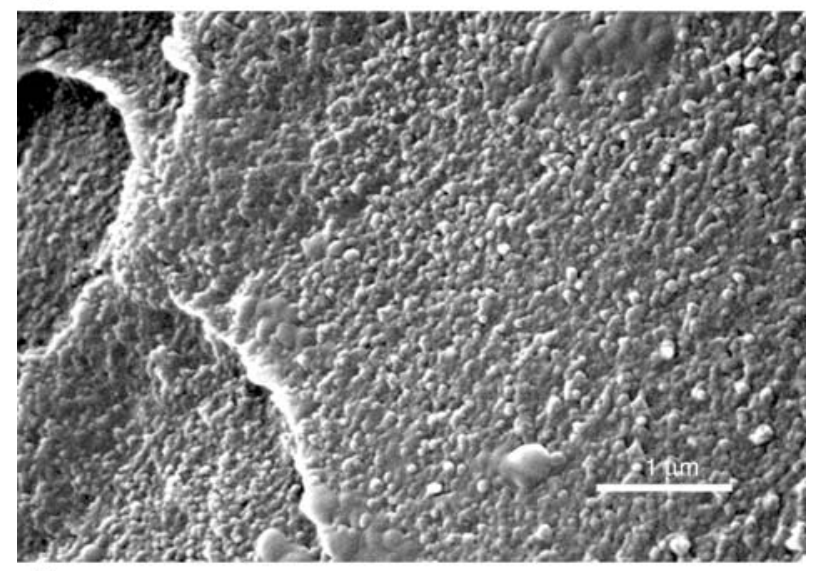

b)

Figure 3. SEM micrographs of PI/silica hybrids with 22.3 wt $\%$ of silica: a) hybrid without the coupling agent (GOTMS); b) hybrid with the coupling agent (GOTMS) [28]. 
$100 \mathrm{~nm}$, while for the non-compatibilized system, the average diameter of the silica particles varies from 0.8 to $1.0 \mu \mathrm{m}$. These morphologies are the result of a typical phase separation by spinodal decomposition [30, 31] differing from each other in the extent of phase connectivity. The way through which the coupling agent induces and controls the evolution of the morphology in these hybrid sys-

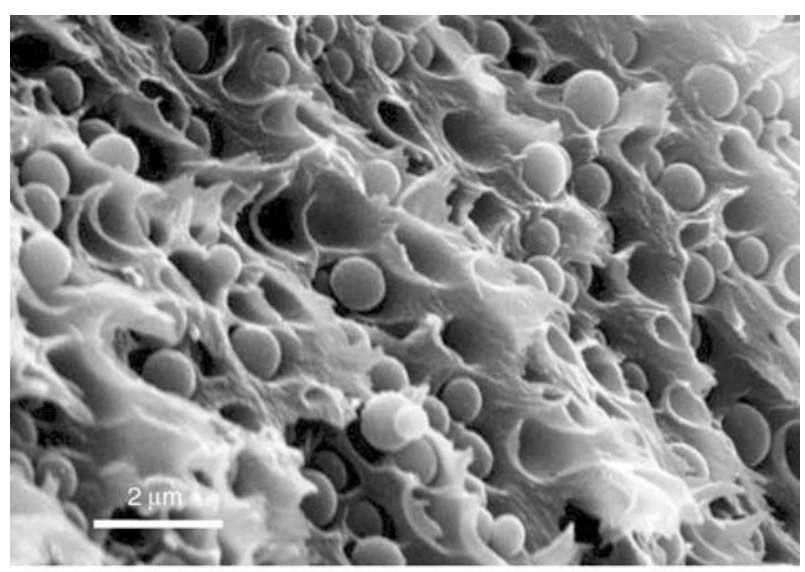

a)

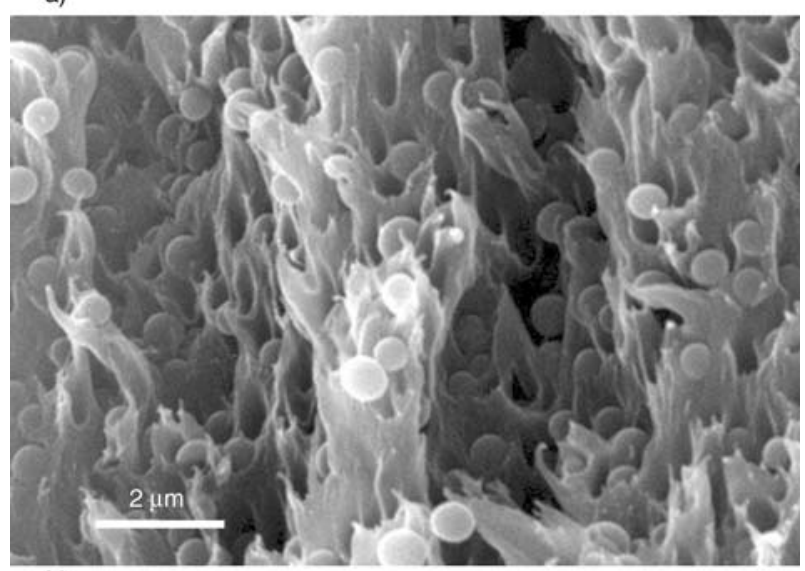

b)

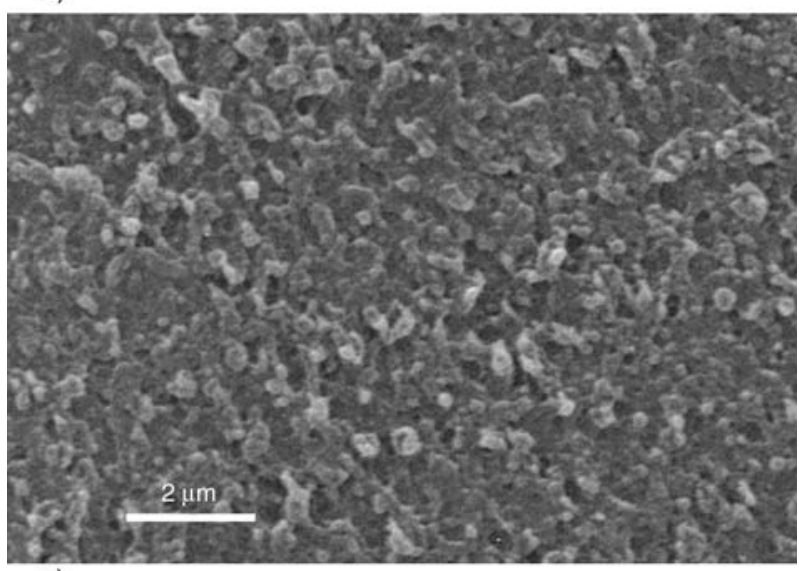

c)

Figure 4. SEM micrographs of PI/silica hybrids with $22.3 \mathrm{wt} \%$ of silica and at different GOTMS/TEOS molar ratios: a) GOTMS/TEOS 0.02 ; b) GOTMS/TEOS 0.03; c) GOTMS/TEOS 0.1 [32]. tems was attributed to interactions, possibly by hydrogen bonding, taking place between the epoxy groups of GOTMS and the acid groups of the polyimide precursor. These interactions delay the onset of phase separation by spinodal decomposition, which results in a higher viscosity of the solution and in a reduction of the rate of particle growth [5, $8,32]$. It was found that a threshold value of the GOTMS/TEOS molar ratio exists for the formation of co-continuous morphologies $[8,32]$. This threshold value was found to change with the overall silica content in the hybrid. For a silica concentration of $22.3 \mathrm{wt} \%$, calculated theoretically assuming complete conversion of TEOS and GOTMS to silica [33], the threshold GOTM/TEOS molar ratio is located between 0.06 and 0.08 . Figure 4 shows the SEM micrographs of hybrids having $22.3 \mathrm{wt} \%$ of silica and GOTMS contents below and above the threshold value [32]. For GOTMS concentrations lower than the limiting value, the hybrids display (Figures $4 \mathrm{a}$ and $4 \mathrm{~b}$ ) a particulate morphology like that of Figures 3a, but with smaller particles sizes. The dimensions of these particles decrease from about 0.61 to $0.32 \mu \mathrm{m}$ with increasing the amount of GOTMS. The micrograph of Figure $4 \mathrm{c}$, on the other hand, illustrates the morphology obtained with a GOTMS content slightly above the threshold value. This morphology is close to that of Figure $3 b$ for which a higher GOTMS concentration was used. TEM examinations for co-continuous structures revealed additional morphological features. In particular, it was found that increasing the amount of GOTMS above the threshold value had the effect of reducing the sizes of the silica domains [33]. Thus the GOTMS/TEOS molar ration represents a parameter which allows us to finely tune the size of the silica particles in the system. This flexibility in the management of the final morphology permits to realize PI/silica hybrids tailored to specific requirements. For instance co-continuous morphologies were found to be much more effective in suppressing molecular relaxation processes, producing higher temperature stability and lower coefficients of thermal expansion. Two-phase micron sized morphologies, on the other hand, gave higher ductility.

Attempts to decrease the extent of phase separation in PI/silica hybrids by enhancing the miscibility of the components were also conduced by Wang and coworkers [23, 34, 35]. They used aminophenyl- 
trimethoxysilane (APTMOS) as a coupling agent. Whether premixed with the polyamic acid or with the trimethoxysilane (TMOS) solution, this coupling agent was reported to have improved the dispersion of the silica domains in the polyimide matrix. This was attributed to the enhanced interconnectivity of the two phases through chemical interactions with the amine groups of the coupling agent.

Hybrids from TMOS and a pyromellitic polyamic acid, synthesised by replacing the aromatic diamine typically used (ODA) with $\gamma$-aminopropyltrimethoxysilane (APTEOS) have been also investigated by Schrotter et al. [36]. The resulting microstructure of PMDA/APTEOS-based films showed a better incorporation of the silica than in PMDA/ODA, possibly as a result of the presence of active amino and methoxyl groups in APTEOS [37]. Using a variety of other amine coupling agents, the same authors demonstrated the variability in the siloxane network density, according to the precursor used. Generally, in the absence of alkoxyl functionalities, in favour of methyl groups, linear materials were produced. Conversely, methyl groups imparted hydrophobic character to the final materials.

\section{Reactivity and curing behaviour}

Several investigations have been reported in which the influence of the inorganic phase on the reactivity of the polyimide precursor has been studied [28, 29,38 ]. In all these reports it has been pointed out that the silica phase exerts a considerable influence on the behaviour of the polyamic acid both in terms of its tendency to form molecular interactions with residual solvent, and with respect to the imidization reaction itself. In particular, Musto et al. [28] performed a time-resolved FTIR analysis on a PI/silica nanocomposite and a pure polyimide (PMDAODA) in order to compare the rate and extent of solvent removal from the two systems. It was shown that the presence of the silica precursor within the pre-polymer solution greatly facilitates solvent removal from the film surface. This effect was ascribed to a reduction of the stability of the NMP-PI complexes and, in particular to the destabilization of the most stable complex, i.e. the one with a 1:2 PI repeating units/NMP molar ratio. It was speculated that the comparatively large amount of
$\mathrm{OH}$ groups present on the silica phase effectively compete with NMP in forming hydrogen-bonding interactions with the PAA units. The same spectroscopic technique was employed to investigate the kinetics of thermal imidization. In this instance the imidization degree, i.d., was evaluated by monitoring the intensity of the imide band at $1376 \mathrm{~cm}^{-1}$ as a function of time. The i.d. parameter, relative to three different systems, is reported in Figure 5 as a function of the reaction time. In particular, curve A refers to a nanocomposite with $22.3 \mathrm{wt} \%$ of silica, curve $\mathrm{B}$ is for the pure polyimide precursor and curve $\mathrm{C}$ is relative to a PAA film from which the NMP solvent was completely removed before curing. The kinetic data for the imidization of the polyimide precursor, shown in Figure 5, curve B, are in general agreement with other published results. In particular, two distinct regimes can be distinguished; both being adequately described as first order processes. The initial regime is faster than the second by a factor of about 6.5 . It also worth to note that partial imidization (i.d. $=0.06$ ) takes place during the heating ramp before reaching the isothermal temperature. For this reason the conversion curve does not start from the origin. The data shown in Figure 5, curve C, relative to a PAA film from which all NMP had been eliminated prior to curing, confirm the fundamental role of residual solvent in the cure kinetics of polyimides. In fact, a drastic reduction of the imidization rate is observed in

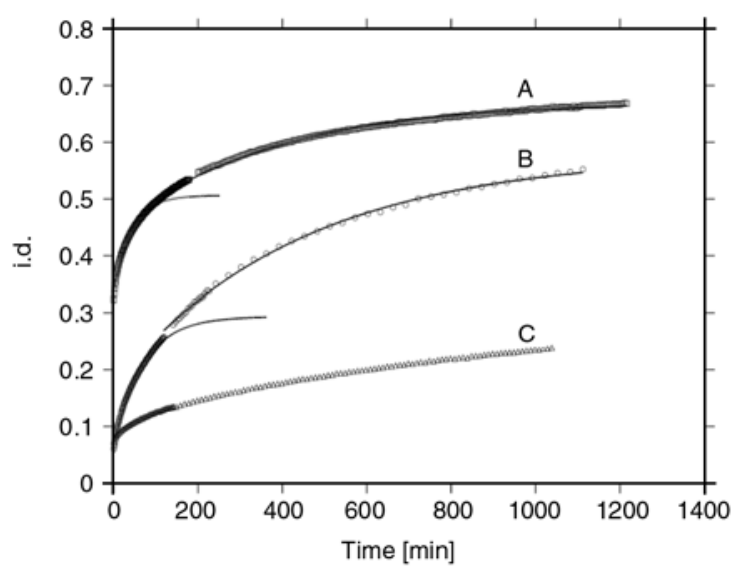

Figure 5. Imidization degree (i.d.) as a function of time for the isothermal reaction at $120^{\circ} \mathrm{C}$. Curve A: nanocomposite with $23.3 \mathrm{wt} \%$ of silica. Curve B: polyimide precursor. Curve C: polyimide precursor from which the solvent had been completely eliminated prior to curing. The symbols indicate the experimental data, while the continuous lines represent the simulation of the first order kinetic model [29]. 
comparison to the control system (compare curves $\mathrm{B}$ and $\mathrm{C}$ ). The kinetic behaviour of the nanocomposite precursor resembles that of the pure polyamic acid in the presence of solvent, in that it can be adequately described by two first-order regimes. The second regime has a rate constant considerably lower than that of the first regime. However, in the nanocomposite system the first stage is significantly faster than for the pure polyamic acid in solution and the imidization reaches a more advanced stage during the heating ramp from room temperature to $120^{\circ} \mathrm{C}$ (initial i.d. $=0.33$ ). As a consequence of these two effects the final conversion of amic acid is higher in the nanocomposite than in the pure polyimide polyimide ( 0.67 against 0.58 ). The second stage of imidization in the two systems, however, is characterized by a comparable rate constant. The kinetic behaviour for the nanocomposite precursor seems to be conflicting with the solvent effect, since the residual amount of solvent is much lower in the nanocomposite formulation than in the in pure polyamic acid solution. Evidently, the inorganic phase exerts a catalytic activity with respect to the imidization of polyamic acid. This effect may arise from the hydroxyl groups present along the outer surface of the silica phase. These may form strong molecular interactions of the hydrogen bonding type with the amic acid moieties of PAA and, in doing so, may force the PAA chains to assume a planar conformation more favourable for cyclization.

\section{Dynamic mechanical properties}

Dynamic mechanical analysis (DMA) has been extensively used to study the influence of the silica phase on the molecular relaxation processes of the polyimide, which control and determine several material properties including tensile mechanical properties [39-41].

Figures 6 and 7 report the DMA results obtained by Musto et al. [42] on two types of PI/silica hybrids having, respectively, a particulate micron sized structure and nano-structured co-continuous morphology. The alkoxysilane solutions used for the production of these hybrids were pure TEOS for the phase separated system and a TEOS/GOTMS mixture for the interconnected hybrid. The PI precursor was a PAA formed by condensation of PMDA and ODA.

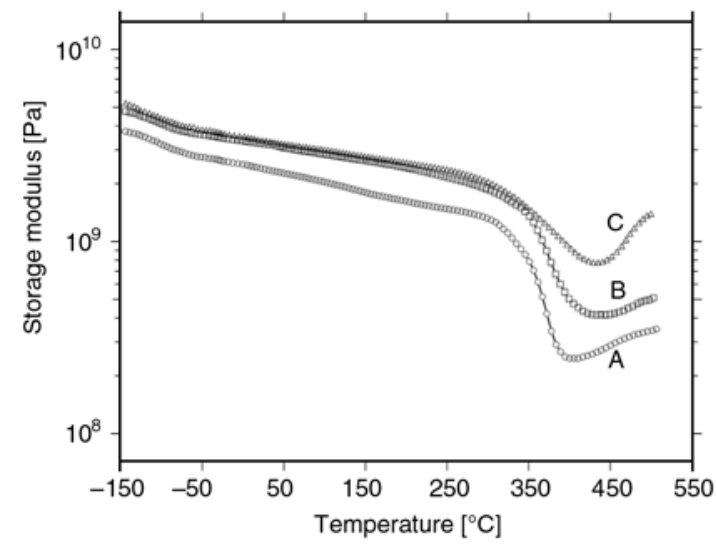

Figure 6. Storage modulus as a function of temperature: A) pure polyimide; B) microcomposite with $22.3 \mathrm{wt} \%$ of silica; C) nanocomposite with $22.3 \mathrm{wt} \%$ of silica [42].

The presence of silica increases the elastic modulus (Figure 6) both in the glassy region and at temperatures above the glass transition. The upturn in the $E^{\prime}$ curves above the glass transition was attributed to the occurrence of intermolecular crosslinking reactions.

The tan $\delta$ plots (Figure 7) reveal the occurrence of three relaxation processes with increasing tempera-
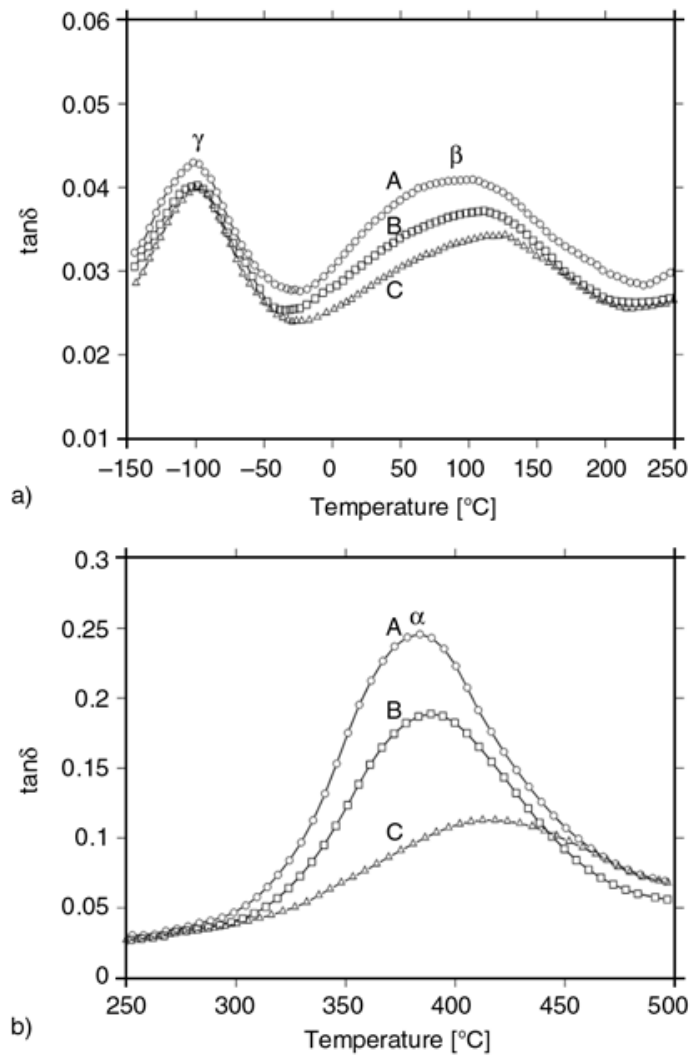

Figure 7. Tan $\delta$ spectra as a function of temperature: A) pure polyimide; B) microcomposite with $22.3 \mathrm{wt} \%$ of silica; C) nanocomposite with $22.3 \mathrm{wt} \%$ of silica [42]. 
ture. The low and the medium temperature relaxations are defined, respectively, as the $\gamma$ and $\beta$ transitions (Figure 7a). The highest temperature transition is an $\alpha$-relaxation process (Figure $7 b$ ) and corresponds to the glass transition temperature $\left(T_{g}\right)$. The $\beta$ transition is generally associated with local bond rotations along the polyimide backbone, although its exact description is still uncertain [42]. The $\gamma$ transition is observed only in the presence of absorbed moisture.

The incorporation of the silica phase causes a shift of the $\gamma, \beta$ and $\alpha$ peaks toward higher temperatures. The increase in $T_{\beta}$ and $T_{\alpha}$ was about $10^{\circ} \mathrm{C}$ for the micron sized composite and, respectively, of 24 and $34^{\circ} \mathrm{C}$ for the nanocomposite. The increase in $T_{\gamma}$ was considerably lower. Also the height of these transitions decreases. The effect was larger for the $\beta$ and $\alpha$ processes and was much more pronounced for the nanocomposite sample. This depression in the relaxation processes was attributed to an increased constrain of the polyimide chain segments due to occurrence of interactions between the silica phase and the polyimide matrix. These interactions are larger for the nanocomposite than for microcomposite and were attributed to the action of the GOTMS coupling agent.

On the same systems Mascia and Kioul [8] found that for phase separated hybrids the depression of the $\alpha$-relaxations was approximately equal to that predicted by the law of mixtures, showing that all the silica precipitated as spherical particles. For nanocomposites, on the other hand, the reduction in the $\alpha$-relaxations was considerably lower. This was indicative of the involvement of polyimide chains in the silicate network through the coupling of the two components by the GOTMS.

The effect of the silica precursor on the $\beta$ and $\alpha$ relaxation processes was also studied by Cornelius and Marand [40]. They produced a series of hybrids by carrying out sol-gel reactions of different alkoxysilanes in the presence of fully imidized polyimides, functionalized with different degrees of triethoxysilane groups. The alkoxysilanes employed included tetramethoxysilane (TMOS), methyltrimethoxysilane (MTMOS), and phenyltrimethoxysilane (PTMOS).

The morphology of these hybrids was found to be largely dependent on the type and content of the alkoxide used. In particular, the higher functionality and reactivity of TMOS gave rise to very fine interconnected homogeneous systems, while the MTMOS and PTMOS based hybrids were phase separated with micron sized silica domains.

The DMA results revealed that the $T_{g}$ and the $T_{\beta}$ of various hybrid materials increased with increasing silica content. However, no clear trends with type or concentration of the alkoxide was observed. On the other hand, the magnitude of $\tan \delta$ at $T_{g}$ was found to decrease with increasing the silica content for all the hybrid systems. The larger $T_{g}$ reduction was displayed for the TMOS based hybrids, followed by MTMOS and PTMOS hybrids. These results confirm that, as found for TEOS/GOTMS based hybrids, highly interconnected morphologies are much more effective in depressing $\alpha$-relaxations with respect to phase separate systems.

In accordance with the DMA results, larger reductions in the coefficient of thermal expansion were found when the morphology of the dispersed silica phase changed from particulate to co-continuous [8]. This effect became even more pronounced at temperatures above the $T_{g}$ of the PI.

\section{Mechanical and fracture properties}

Polyimide/silica hybrids generally exhibit improved mechanical properties when compared to those of pristine polyimides. These enhancements include primarily modulus, strength and toughness and the magnitude of the effect is related to the compatibility of the organic and inorganic components, as well as to the size and dispersion state of the inorganic phase.

In Figures 8 and 9 are shown the results of tensile tests carried out by Musto et al. [28] on PI/silica systems obtained using GOTMS as compatibilizing agent. The modulus is found to increase linearly with increasing the concentration of the inorganic phase (Figure 8). In the same figure, the data for the normalized modulus, calculated as the ratio of the modulus of the hybrid to that of the polyimide, reached a value of 2 (i.e. $100 \%$ increase) at a silica content of $28.4 \%$. This enhancement was found to be larger than that normally achieved for conventional composites [43,44]. The tensile strength (Figure 9) showed a gradual increase up to a concentration of silica around $15 \mathrm{wt} \%$, followed by a slight reduction at higher concentrations. The elongation at break, displayed in the same figure, exhibited a monotonic decrease. The increase in the 


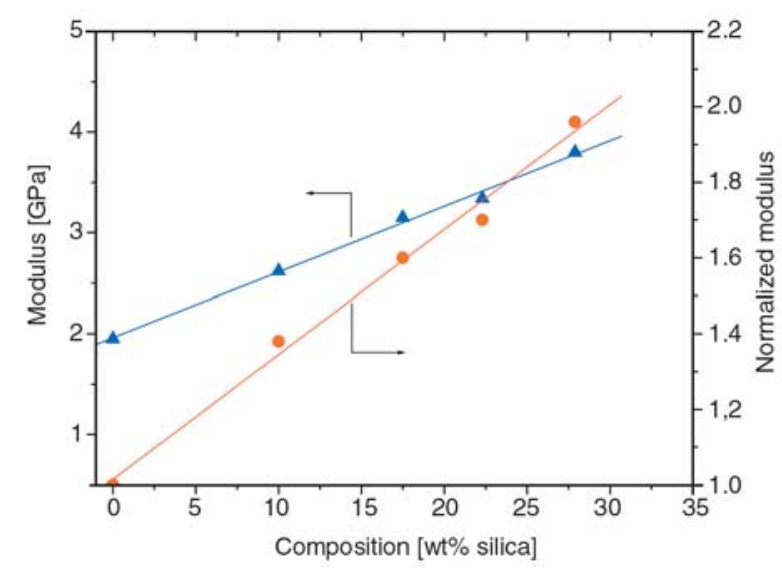

Figure 8. Elastic modulus $(\boldsymbol{\Delta})$ and normalized elastic modulus (•) for nanocomposite hybrids as a function of the silica content [28].

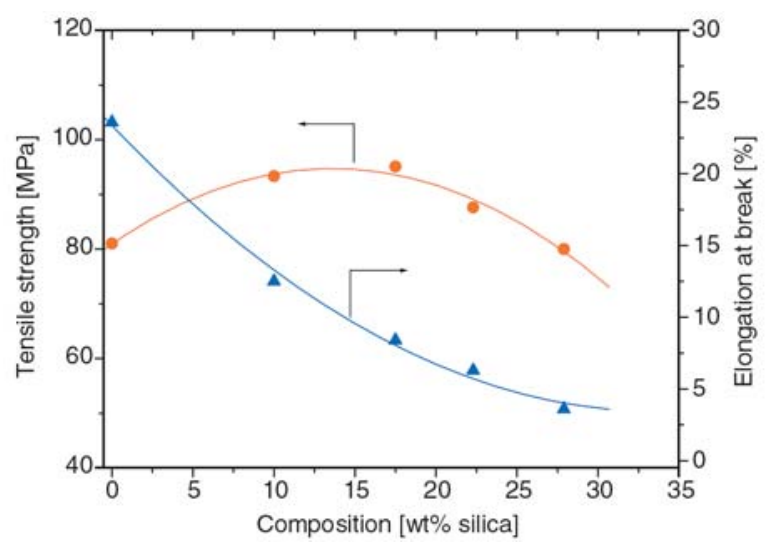

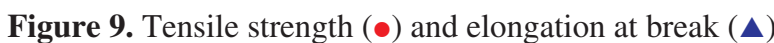
for nanocomposite hybrids as a function of the silica content [28].

mechanical strength was attributed to the action of GOTMS, which produced both an improvement in the interfacial adhesion and the formation of finely interconnected morphologies (see Figure 3b), leading to an efficient stress transfer mechanism between the two components. This is consistent with the fact that tensile strengths are known to be reduced if there are no interactions between the organic matrix and the inorganic phase. Chen et al. [45] also reported hybrids with a co-continuous phase morphology obtained directly from a soluble PI, functionalized with phenyl hydroxyl groups, and GOTMS as compatibilizer. In Figure 10 are compared the mechanical properties of $\mathrm{PI} /$ silica systems obtained with GOTMS (PHC) and without GOTMS (PHA). In both cases the tensile strength (Figure 10a) and the elongation at break (Figure 10b) increase with increasing the silica content up to a concentration of about $15 \mathrm{wt} \%$. After that a fast reduction is observed. Although for both sys-
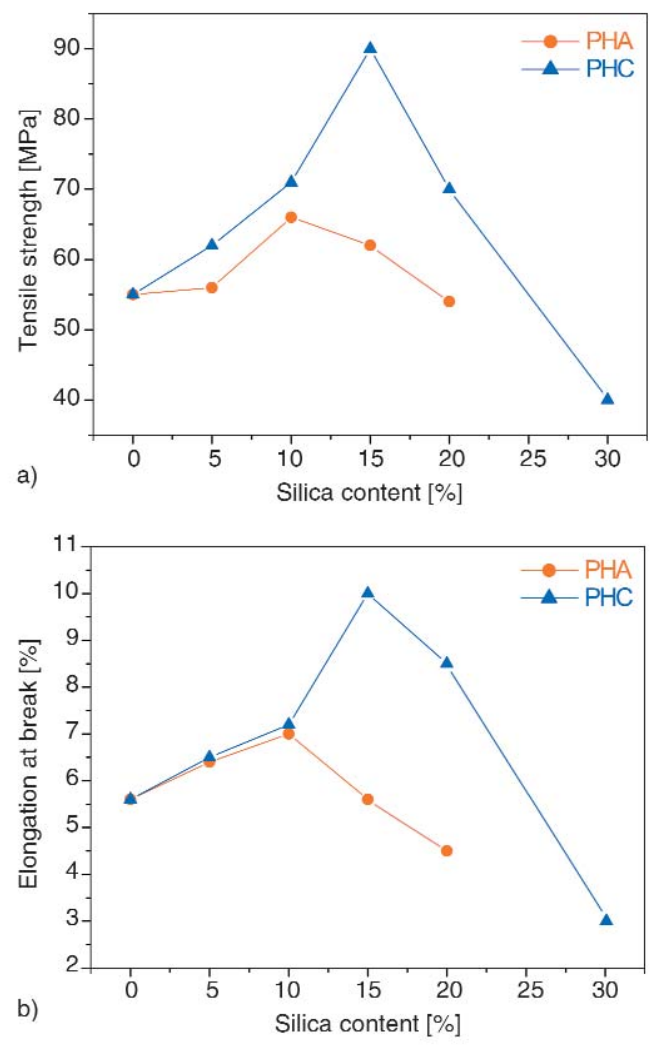

Figure 10. Mechanical properties of PI/silica hybrids with GOTMS (PHC) and without GOTMS (PHA) as a function of silica content: a) Tensile strength; b) Elongation at break. Reproduced from [45] Chen B. C., Chin T. M., Tsay S. Y., by permission of John Wiley \& Sons, Ltd.

tems the introduction of hydroxyl groups in the PI increased the miscibility with the silica phase, the superior mechanical properties exhibited by the PHC hybrids were the result of a better compatibility and interfacial strength achieved through the formation of chemical bonds involving the hydroxyl groups of PI and the epoxy groups of the GOTMS.

Changes in the type of coupling agent were found to produce hybrid materials with mechanical properties comparable to those achieved with GOTMS. In this regard several aminoalkoxylanes, including aminopropyltriethoxysilane (APTEOS) and aminophenyltrimethoxysilane (APTMOS) were employed. The presence of both amino and methoxy side groups enabled chemical bonding between the PI and silica, resulting in the formation of homogeneous hybrids with enhanced modulus and ultimate properties. This is shown in Figure 11 where the results of Zhang et al. [46] on hybrids containing APTEOS are reported. It can be seen that for silica 


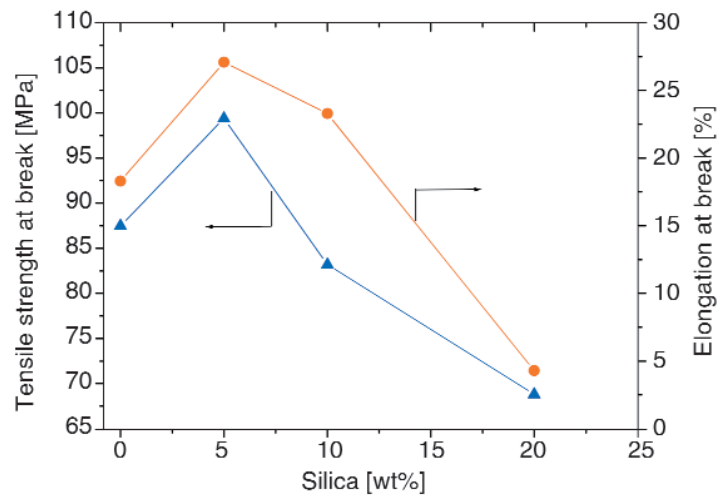

Figure 11. Tensile strength and elongation at break as a function of silica content. Reproduced from [46] Zhang J., Zhu B. K, Chu H. Y., Xu Y. Y, by permission of John Wiley \& Sons Ltd.

contents lower than $10 \mathrm{wt} \%$ improvements in the ultimate properties are observed, while for silica concentrations exceeding this value both tensile strength and elongation at break sharply decrease. Chen and Iroh [47] also used APTEOS for the production of bonded PI-silica hybrids. These materials exhibited, in comparison with the pure polyimide, higher mechanical strengths and lower elongations at break. Similarly Ahmad et al. [23] used APTMOS to bond the PI to the silica phase. This aromatic compound was also chosen for its high thermal stability, which is comparable to that of the pure polyimide. Relatively small amounts of APTMOS were found to improve significantly modulus and mechanical strength.

The effect of temperature on the mechanical properties of PI/silica nanocomposites was also investigated [28]. In Figure 12 the variation of modulus with temperature for a nanocomposite hybrid containing $22.3 \%$ of silica is compared with that of the pure PI. The relevant finding is that at $250^{\circ} \mathrm{C}$, which is the limiting temperature for the continuous use of polyimides, the value of modulus of the hybrid material is very close to that of the neat polyimide at ambient temperature. An analogous trend was observed for the tensile strength (Figure 13). Thus, properly formulated PI hybrids with silica domains of nanoscale dimensions could make it possible to extend considerably the maximum temperature at which these systems can be reliably employed.

Ragosta and coworkers [32, 48] used the Essential Work of Fracture (EWF) method [49-51] to assess the fracture toughness of phase separated PI/silica hybrids from ambient temperature to $250^{\circ} \mathrm{C}$. Fig-

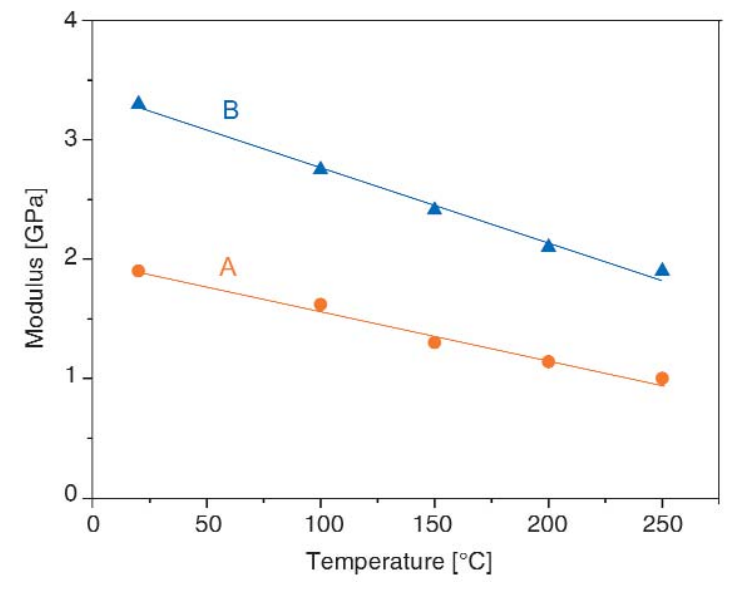

Figure 12. Elastic modulus as a function of temperature for the plain polyimide (Curve A) and for a nanocomposite with 22.3 wt $\%$ of silica (Curve B) [28].

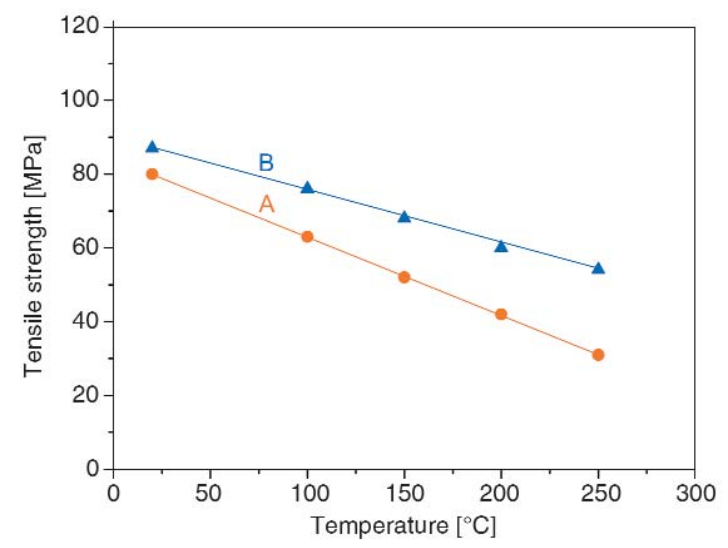

Figure 13. Tensile strength as a function of temperature for the plain polyimide (Curve A) and for a nanocomposite with $22.3 \mathrm{wt} \%$ of silica (Curve B) [28].

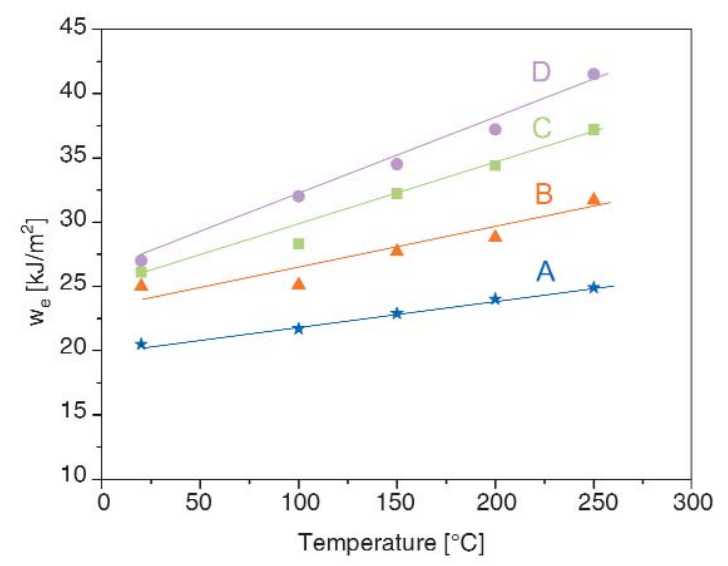

Figure 14. Essential work of fracture, $w_{e}$, as a function of temperature: A) polyimide; B) microcomposite with $10 \mathrm{wt} \%$ of silica; C) microcomposite with $15 \mathrm{wt} \%$ of silica; D) microcomposite with $20 \mathrm{wt} \%$ of silica [48]. 


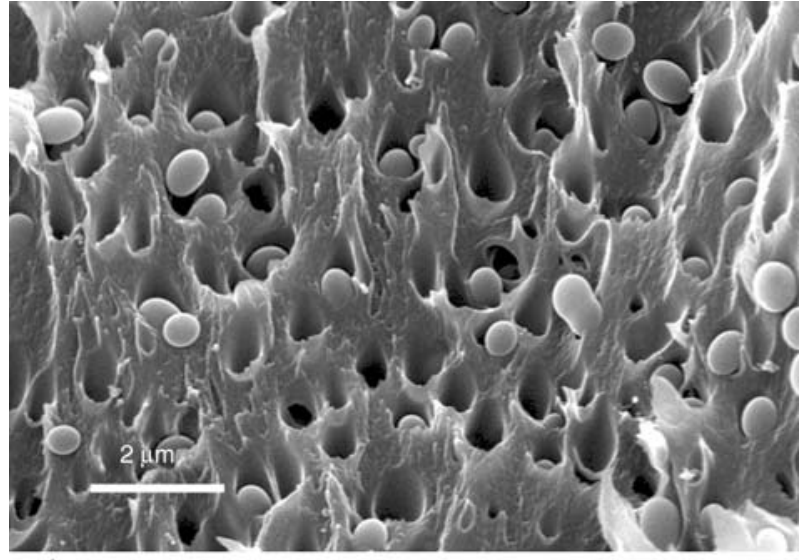

a)

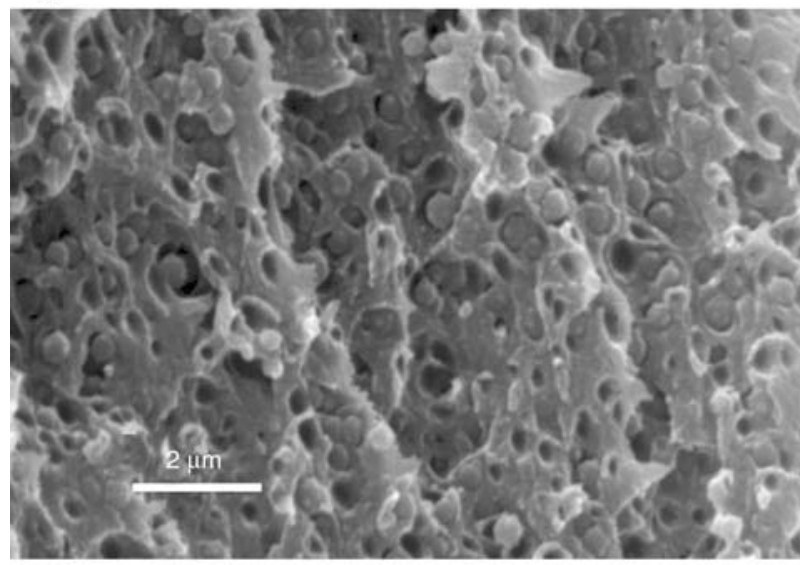

b)

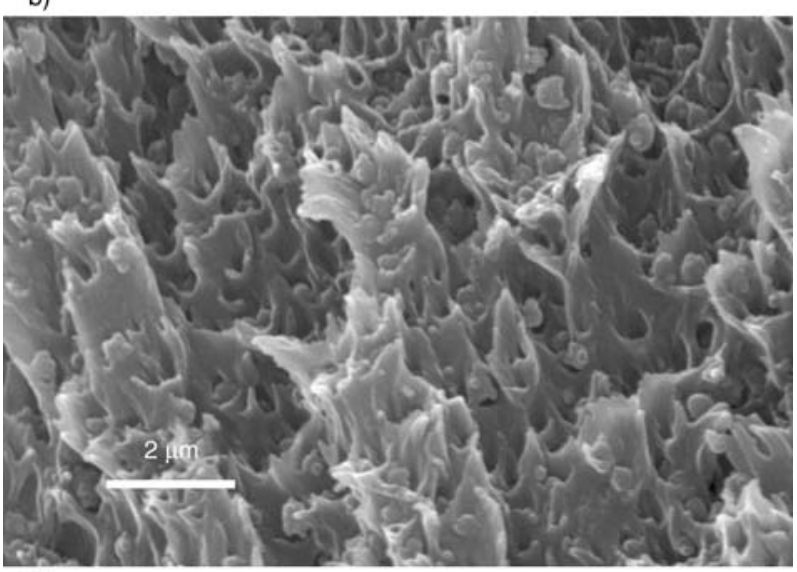

c)

Figure 15. SEM micrographs of the fractured surfaces of particulate composites with $15 \mathrm{wt} \%$ of silica, tested at ambient temperature:

a) GOTMS/TEOS 0,0; b) GOTMS/TEOS 0.03;

c) GOTMS/TEOS 0.04 [32].

Table 1. The essential work of fracture, $w_{e}$, for microcomposites containing $15.0 \mathrm{wt} \%$ of silica and different GOTMS/TEOS molar rations

\begin{tabular}{|c|c|c|c|}
\hline $\begin{array}{c}\text { Silica content } \\
{[\mathbf{w t} \%]}\end{array}$ & $\begin{array}{c}\text { GOTMS/TEOS } \\
{[\text { molar ratio] }}\end{array}$ & $\begin{array}{c}\mathbf{w}_{\mathbf{e}} \\
{\left[\mathbf{k J} / \mathbf{m}^{2}\right]}\end{array}$ & $\begin{array}{c}\text { Temperature } \\
{\left[{ }^{\circ} \mathbf{C}\right]}\end{array}$ \\
\hline 15.0 & 0.00 & 26.5 & 20 \\
\hline 15.0 & 0.03 & 28.2 & 20 \\
\hline 15.0 & 0.04 & 30.4 & 20 \\
\hline
\end{tabular}

ure 14 shows the fracture toughness, expressed in term of the essential work of fracture parameter, $w_{e}$, versus temperature for a series of particulate $\mathrm{PI} / \mathrm{sil}-$ ica hybrids and for the pure polyimide. The parameter, $w_{e}$, is found to increase linearly with increasing temperature and, at any given temperature, the enhancement of fracture toughness is related to the silica content. It is also found, as shown in Table 1, that for a given silica content the fracture toughness increases further when the GOTMS coupling agent is added to silica precursor.

The fractographic analysis (Figure 15) shows that the fracture process of these hybrids is dominated by interface-initiated cavitations. This mechanism is known to occur in particulate composites with spherical particles when the matrix modulus is lower than that of the particles $[52,53]$. In particular, due to the poor adhesion between particles and matrix, a debonding process takes place at both equator and pole regions of the particles. The debonding of the matrix from the particles relaxes the local interfacial stresses promoting shear yielding mechanisms. Thus cavitations and matrix yielding are the deformation mechanisms responsible for the enhancement in the fracture toughness observed for micron sized PI/ silica hybrids.

The addition of GOTMS (compare Figure 15a with Figures $15 \mathrm{~b}$ and $15 \mathrm{c}$ ) reduces the particles diameter and improves the interfacial strength, thus favouring the conditions for promoting shear yielding processes in the PI matrix. Accordingly, higher values of $w_{e}$ are found with respect to those in absence of GOTMS (see Table 1).

\section{Applications}

The applications areas for PI/silica hybrids have considerably expanded with the current generation of materials in microelectronic, optoelectronic, and advanced membranes [54-57]. Some specific examples will be now briefly described on these particular uses.

Ree et al. [58] prepared PI/silica nanocomposite hybrids for the production of microelectronic devices utilizing silica aerogels, which are known to exhibit a low dielectric constant and low thermal expansivity [59]. These hybrids showed improved dielectric and optical properties, whereas the interfacial stress and the thermal expansion coefficient were found considerably reduced owing to the sil- 
ica aerogels despite their low thermal expansivity. Kim et al. [60] studied the effects of TEOS content on the dielectric properties of PI hybrids using two type of soluble precursors chemically convertible to PI [poly(p-phenylene biphenyltetracarboxamic acid) (BPDA-PDA) and BPDA-PDA diethyl ester (BPDA-PDA ES)]. It was found that BPDA-PDA gave homogeneous nanocomposite films, whereas heterogeneous micron sized hybrids were generated with the BPDA-PDA ES precursor. As shown in Figure 16 the dielectric properties increased with TEOS contents, regardless of the polyimide precursor type, due to the inherent higher dielectric constant of silica in comparison to that of the PI. However, the nanocomposites films exhibited higher dielectric constants than those of microcomposites. Accordingly, the decrease in the resistivity observed in these hybrids was found to be less prominent for the nanocomposites than that for the microcomposites. Jiang et al. [61] developed a new method for preparing PI/silica films with low dielectric constants. The procedure consisted in two steps. Firstly, PI/silica hybrids were prepared via a sol-gel process. Secondly, the hybrid films were treated with hydrofluoric acid to remove the dispersed silica phase, leaving pores with a size and shape dictated by the initial morphology. It was found that the porous films exhibited lower dielectric constants with respect to the PI/silica hybrids, owing to the presence of air in the pores. Recently, there has been a great deal of interest in using polysilsesquioxane (PSSQ) or poly (vinylsilsesquioxane) (PVSSQ) as novel inorganic components in

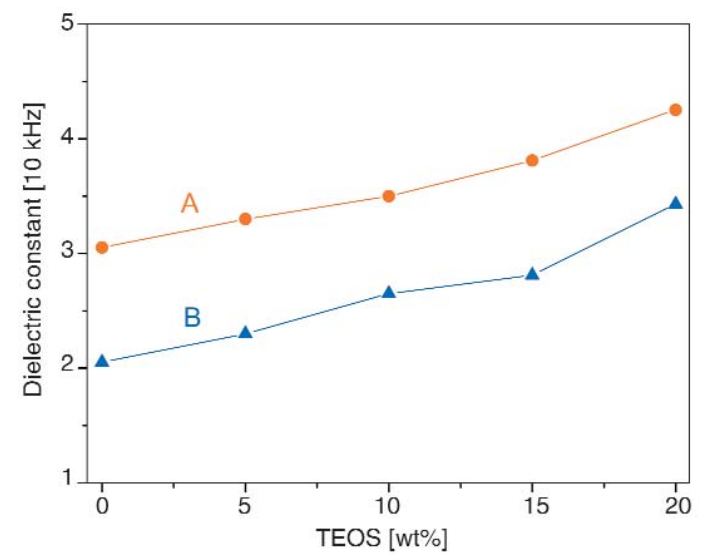

Figure 16. The effect of TEOS on the dielectric constant of silica/polyimide films: A) BPDA-PDA PAA precursor; B) BPDA-PDA ES precursor. Reproduced from [60] Kim Y., Kang E., Kwon Y. S., Cho W. J., Chang M., Ree M., Chang T., Ha C. S., by permission of Elsevier. the preparation of PI hybrids for microelectronic devices, owing to their lower dielectric constants and lower moisture absorption compared to the silicon dioxide [62-64]. For instance, Wahab et al. [65] produced PI/PVSSQ hybrid films from BPDA-ODA polyamic acid and triethoxyvynilsilane (TEVS). These hybrids exhibited nanocomposite structures for PVSSQ content less than $20 \mathrm{wt} \%$. Figure 17 shows the dielectric constants of the hybrid composites. As small amounts of PVSSQ are added the dielectric constant is remarkably reduced and then it increases with increasing the PVSSQ content. However, even at high PVSSQ contents, the electric constants of the hybrids are still lower than that of the pure polyimide. These hybrids also showed improved mechanical and thermal properties.

PI/silica hybrids were also found to be useful materials for the production of optoelectronic devices (e.g. optical waveguides). For these applications the use of unmodified, conventional photosensitive PIs is strongly limited owing to the large volume shrinkage taking place after curing, which causes a significant distortion on the patterned feature [66]. Therefore, the incorporation of a silica phase within the PI matrix may represent a good solution to overcome this problem. However, only a limited number of PI/silica materials have shown to be photopatternable [67, 68]. For instance, photosensitive PI/silica hybrids were developed by Wang et al. [69]. In this study the volume shrinkage of polyimides with pendant photosensitive moieties, such as 2-methylacrylic acid 2-dimethylaminoethyl ester (MDAE), was largely reduced by pho-

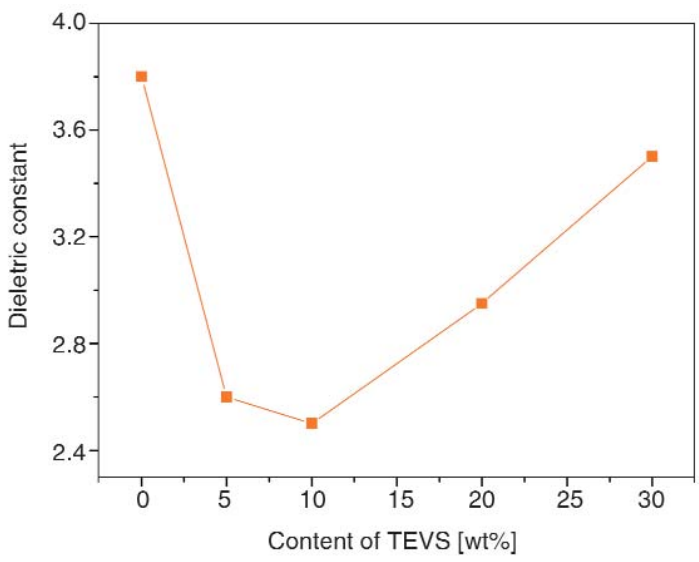

Figure 17. Effect of TEVS contents on the dielectric constants of PI/TEVS hybrid films. Reproduced from [65] Wahab M. A., Kim I., Ha C-S., by permission of Elsevier. 
tocrosslinking MDAE with a coupling agent and the silica domains. The prepared hybrids exhibited good lithographic resolution, dimensional stability, reduced refractive index and low optical loss in the NIR region. Very recently, Yu et al. [70] synthesized fluorinated polyimide/colloidal silica hybrids, using $4.4^{\prime}$-hesafluoroisopropylidenediphthalic anhydride (6FDA), oxydianiline (ODA), aminopropyltriethoxysilane (APTEOS), and colloidal silica, in place of conventional alkoxysilanes. The coupling agent (3-methacryloxypropyl trimethoxysilane, MPTMS) and the silica domains were designed so as to reduce the volume shrinkage and to enhance the thermal properties. The prepared hybrids exhibited lithographical patterns with good resolution, suggesting potential applicability in the field of optoelectronic devices.

Since PI hybrid materials combine the basic properties of organic and inorganic constituents, they can offer specific advantages for the preparation of membranes with enhanced selectivity and permeability, and improved thermal and chemical resistance [71, 72]. In particular, PI/silica membranes have been found to exhibit promising gas permeation qualities and have been tailored to accommodate specific gas separations. Joly et al. [73] conduced a study on transport properties of a series of gases $\left(\mathrm{N}_{2}, \mathrm{O}_{2}, \mathrm{H}_{2}, \mathrm{CO}_{2}\right.$ and $\left.\mathrm{CH}_{4}\right)$ in polyimide hybrids charged with silica particles. The composite membranes showed higher permeability coefficients when compared with the pure polyimide. In spite of the permeability enhancement an increase in the selectivity of the $\mathrm{H}_{2}$ with respect to $\mathrm{N}_{2}, \mathrm{O}_{2}$ and $\mathrm{CO}_{2}$ was observed. In a later paper, Joly et al. [74] investigated the role of silica in the modification of the membrane microstructure and the resulting effects on gas permeability. Similarly, Hu et al. [75] prepared nanocomposite membranes that had higher permeability coefficients and significant improvements in permeselectivity. The diffusivity and selectivity toward gases were also investigated by Cornelius and Marand [76] They prepared, via sol-gel, a series of hybrid composites based on 6FDA-6FpDA and 6FDA-6FDA-DABA polyimides and various organo-silica structures. The gas transport properties of these hybrid membranes were found to be dependent on the type of alkoxide employed and on the final morphology. In particular, systems with low degree of cross-linking between the inorganic and polymer components showed low membrane performances. In contrast, improvements in selectivity and permeability were observed in hybrids with high interactions between the components. This was attributed to the formation of an interphase consisting of constrained polymer segments partially incorporated into the silica structure.

Diffusion studies of ammonia and water vapour in polyimides and polyimide/silica nanocomposite films were conducted by Musto et al. [77-80]. They showed that the amount of hydrogen bonded water increased substantially in these hybrids compared to the pure PI as a result of molecular interactions occurring with the inorganic domains. Extensive reactions were found to take place between the ammonia penetrant and the polyimide substrate, which were considerably faster for the hybrids due to the confinement effect imposed by the nanostructured silica domains. This widens the possibility of utilizing PI hybrid systems for catalytic processes involving reactive penetrants.

\section{Conclusions}

Several examples of polyimide/silica hybrids materials have been presented herein. These showed that the sol-gel process was a versatile tool for the production of such hybrids since it allowed to adapt the structure of the silica phase and the chemical composition of the PI precursor to different applications. The phase separation was found to be the key factor in determining the morphologies that gave the best combination of properties in terms of thermal stability, dynamic and static mechanical properties, and fracture toughness. This can be achieved by promoting interactions between the organic and the inorganic components, either directly by functionalizing the polyimide backbone, or adding coupling agents that interacted with the growing silica network and the PI chains.

\section{References}

[1] Ghosh M. K., Mittal K. L.: Polyimides: Fundamental and applications. Marcel Dekker, New York (1996).

[2] Bessonov M. I., Zubkov V. A.: Polyamic acids and polyimides: Synthesis, transformation and structure. CRC Press, Boca Raton (1993).

[3] Thompson L. F., Wilson C. G,. Tagawa S.: Polymers for microelectronics: Resists and dielectrics. ACS Symposium Series, Washington (1994). 
[4] Mark J. E., Lee C. Y. C., Bianconi P. A.: Hybrids organic-inorganic composites. ACS Symposium Series, Washington (1995).

[5] Kioul A., Mascia L.: Compatibility of polyimide-silicate ceramers induced by alkoxysilane coupling agents. Journal of Non-Crystalline Solids, 175, 169186 (1994).

DOI: $10.1016 / 0022-3093(94) 90009-4$

[6] Mascia L.: Developments in organic-inorganic polymeric hybrids: Ceramers. Trends in Polymer Science, 3, 61-66 (1995).

[7] Morikawa A., Iyoku Y., Kakimoto M., Imal Y.: Preparation of a new class of polyimide-silica hybrid films by sol-gel process. Polymer Journal, 24, 107-113 (1992).

[8] Mascia L., Kioul A.: Influence of siloxane composition and morphology on properties of polyimide-silica hybrids. Polymer, 36, 3649-3659 (1995). DOI: $10.1016 / 0032-3861(95) 93766-\mathrm{F}$

[9] Didier B., Mercier R., Albrola N. D., Bas C.: Preparation of polyimide/silica hybrid material by sol-gel process under basic catalysis: Comparison with acid conditions. Journal of Polymer Science Part B: Polymer Physics, 46, 1891-1902 (2008).

DOI: $10.1002 /$ polb. 21522

[10] Mark J. E., Sun C-C.: Polymer-modified silica glasses. I. Control of hardness. Polymer Bulletin, 18, 259-264 (1987). DOI: $\underline{10.1007 / \mathrm{BF} 00255119}$

[11] Morikawa A., Lyoku Y., Kakimoto M-A., Imai Y.: Preparation of new polyimide-silica hybrid materials via the sol-gel process. Journal of Materials Chemistry, 2, 679-689 (1992). DOI: $10.1039 / \mathrm{JM} 9920200679$

[12] Mark J. E.: Ceramic-reinforced polymers and polymer-modified ceramics. Polymer Engineering and Science, 36, 2905-2920 (1996). DOI: $10.1002 /$ pen. 10692

[13] Mascia L., Zhang Z., Shaw S. J.: Carbon fibre composites based on polyimide/silica creamers: Aspects for structure-properties relationship. Composites Part A: Applied Science and Manufacturing, 27, 12111221 (1996). DOI: $10.1016 / 1359-835 X(96) 00082-6$

[14] Wei Y., Yeh J-M., Jin D., Jia X., Wang J., Jang G-W., Chen C., Gumbs R. W.: Composites of electronically conductive polyaniline with polyacrylate-silica hybrid sol-gel materials. Chemistry of Materials, 7, 969-974 (1995).

DOI: $\underline{10.1021 / \mathrm{cm} 00053 \mathrm{a} 024}$

[15] Guizard C. G., Julbe A. C., Ayral A. J.: Design of nanosized structures in sol-gel derived porous solids. Applications in catalyst and inorganic membrane preparation. Journal of Materials Chemistry, 9, 55-65 (1999).

DOI: $\underline{10.1039 / a 805867 \mathrm{i}}$
[16] Wang H., Zhong W., Xu P., Du Q.: Polyimide/silica/ titania nanohybrids via a novel non-hydrolytic sol-gel route. Composites Part A: Applied Science and Manufacturing, 36, 909-914 (2005).

DOI: 10.1016/j.compositesa.2004.12.008

[17] Nandi M., Conklin J. A., Salvati L. Jr., Sen A.: Molecular level ceramic/polymer composite. 2. Synthesis of polymer-trapped silica and titania nanoclusters. Chemistry of Materials, 3, 201-206 (1991).

DOI: $10.1021 / \mathrm{cm} 00013 \mathrm{a} 040$

[18] Huang H-H., Order B., Wilkes G. L.: Ceramers: Hybrid materials incorporating polymeric/oligomeric species with inorganic glasses by a sol-gel process. Polymer Bulletin, 14, 557-564 (1985).

DOI: $\underline{10.1007 / \mathrm{BF} 00271615}$

[19] Wung C. J., Pang Y., Prasad P. N., Karaz F. E.: Poly( $p$-phenylene vinylene)-silica composite: A novel sol-gel processed non-linear optical material for optical waveguides. Polymer, 32, 605-608 (1991).

DOI: 10.1016/0032-3861(91)90471-T

[20] Wung C. J., Lee K-S., Prasad P. N., Kim J-C., Jin J-I., Shim H-K.: Study of third-order optical non-linearity and electrical conductivity of sol-gel processed silica: Poly(2-bromo-5-methoxy- $p$-phenylene vinylene) composite. Polymer, 33, 4145-4151 (1992). DOI: 10.1016/0032-3861(92)90619-8

[21] Mascia L., Kioul A.: Polyimide-silica hybrid materials by sol-gel processing. Journal of Materials Science Letters, 13, 641-643 (1994). DOI: $\underline{10.1007 / \mathrm{BF} 00271220}$

[22] Nandi M., Conklin J. A. Salviati L. Jr., Sen A.: Molecular level ceramic/polymer composites. 1 . Synthesis of polymer-trapped oxide nanoclusters of chromium and iron. Chemistry of Materials, 2, 772-776 (1990). DOI: 10.1021/cm00012a033

[23] Wang S., Ahmad Z., Mark J. E.: Polyimide-silica hybrid materials modified by incorporation of an organically substituted alkoxysilane. Chemistry of Materials, 6, 943-946 (1994).

DOI: $10.1021 / \mathrm{cm} 00043 \mathrm{a} 013$

[24] Schmidt H.: Inorganic-organic composites by sol-gel techniques. Journal of Sol-Gel Science and Technology, 1, 217-231 (1994). DOI: $10.1007 / \mathrm{BF} 00486165$

[25] Schmidt H., Wolter H.: Organically modified ceramics and their applications. Journal of Non-Crystalline Solids, 121, 428-435 (1990). DOI: 10.1016/0022-3093(90)90171-H

[26] Morikawa A., Jamaguchi H., Kakimoto M., Imai Y.: Formation of interconnected globular structure of silica phase in polyimide-silica hybrid films prepared by the sol-gel process. Chemistry of Materials, 6, 913-917 (1994). DOI: $10.1021 / \mathrm{cm} 00043 \mathrm{a} 009$

[27] Morikawa A., Yamaguchi H., Kakimoto Y., Imai Y.: Preparation of polyimide-silica hybrid films using solgel process. Journal of Photopolymer Science and Technology, 5, 393-396 (1992). DOI: $10.2494 /$ photopolymer.5.393 
[28] Musto P., Ragosta G., Scarinzi G., Mascia L.: Polyimide-silica nanocomposites: Spectroscopic, morphological and mechanical investigations. Polymer, 45, 1697-1706 (2004).

DOI: 10.1016/j.polymer.2003.12.044

[29] Abbate M., Musto P., Ragosta G., Scarinzi G., Mascia L.: Polyimide-silica hybrids: Spectroscopy, morphology and mechanical properties. Macromolecular Symposia, 218, 211-220 (2004).

DOI: $10.1002 /$ masy.200451422

[30] Inoue T.: Reaction-induced phase decomposition in polymer blends. Progress in Polymer Science, 20, 119-152 (1995). DOI: 10.1016/0079-6700(94)00032-W

[31] Yamanaka K., Takagi Y., Inoue T.: Reaction-induced phase separation in rubber-modified epoxy resins. Polymer, 30, 1839-1844 (1989). DOI: $10.1016 / 0032-3861(89) 90355-8$

[32] Ragosta G., Musto P., Abbate M., Russo P., Scarinzi G.: Effect of morphology on the relaxation processes and mechanical properties in polyimide/silica hybrids. Macromolecular Symposia, 247, 88-98 (2007). DOI: $10.1002 /$ masy.200750111

[33] Menoyo C. J. D., Mascia L., Shaw S. J.: Compatibilization mechanism of polyimide/silica hybrids with organofuctional trialkoxysilanes. in 'Nanostructured powders and their industrial applications' (eds.: Beaucage G., Mark J. E., Burns G. T., Hua D. W.) Vol 520, 239-267, Materials Research Society, Warrendale (1998).

[34] Wang S., Ahmad Z., Mark J. E.: Polyimide-silica hybrid materials having interfacial bonding through use of a sol-gel technique. Journal of Macromolecular Science, Macromolecular Reports, 31, 411-419 (1994).

[35] Mark J. E., Wang S., Ahmad Z.: Inorganic-organic composites, including some examples involving polyamides and polyimides. Macromolecular Symposia, 98, 731-741 (1995).

[36] Schrotter J. C., Smaihi M., Guizard C.: Polyimidesiloxane hybrid materials: Influence of coupling agents addition on microstructure and properties. Journal of Applied Polymer Science, 61, 2137-2149 (1996).

DOI: $\underline{10.1002 /(S I C I) 1097-4628(19960919) 61: 12}$ $\leq 2137:$ :AID-APP12>3.0.CO;2-4

[37] Goizet S., Schrotter J. C., Smaihi M., Deratani A.: Sol-gel polyimide-silica composite films: Correlation between the microstructure and the synthesis parameters. New Journal of Chemistry, 21, 461-468 (1997).

[38] Tyan H-L., Liu Y-C., Wei K-H.: Enhancement of imidization of poly(amic acid) through forming poly(amic acid)/organoclay nanocomposites. Polymer, 40, 4877-4886 (1999).

DOI: $10.1016 / \mathrm{S} 0032-3861(98) 00716-2$
[39] Wang L., Tian Y., Ding H., Li J.: Microstructure and properties of organosoluble polyimide/silica hybrid films. European Polymer Journal, 42, 2921-2930 (2006).

DOI: $10.1016 / j$.eurpolymj.2006.08.004

[40] Cornelius C., Marand J. E.: Hybrid inorganic-organic materials based on a 6FDA-6FpDA-DABA polyimide and silica: Physical characterization studies. Polymer, 43, 2385-2400 (2002). DOI: $10.1016 / \mathrm{S} 0032-3861(01) 00803-5$

[41] Matos M. C., Ilharco L. M., Almeida R. M.: The evolution of TEOS to silica gel and glass by vibrational spectroscopy. Journal of Non-Crystalline Solids, 147-148, 232-237 (1992). DOI: $10.1016 / \mathrm{S} 0022-3093(05) 80622-2$

[42] Musto P., Abbate M., Lavorgna M., Ragosta G., Scarinzi G.: Microstructural features, diffusion and molecular relaxations in polyimide/silica hybrids. Polymer, 47, 6172-6186 (2006). DOI: $10.1016 /$ j.polymer.2006.05.074

[43] Iyoku Y., Kakimoto M., Imai Y.: The preparation of poly(methylsilsesquioxane) network-polyimide hybrid materials by the sol-gel process and their properties. High Performance Polymers, 6, 43-52 (1994). DOI: $10.1088 / 0954-0083 / 6 / 1 / 005$

[44] Magaraphan R., Lilayuthalert W., Sirivat A., Schwank J. W.: Preparation, structure, properties and thermal behaviour of rigid-rod polyimide/montmorillonite nanocmposites. Composites Science and Technology, 61, 1253-1264 (2001). DOI: $10.1016 / \mathrm{S} 0266-3538(01) 00026-4$

[45] Chen B-K., Chin T-M., Tsay S-Y.: Synthesis and characterization of polyimide/silica hybrid nanocomposites. Journal of Applied Polymer Science, 94, 382 393 (2004).

DOI: 10.1002/app.20947

[46] Zhang J., Zhu B-K., Chu H-Y., Xu Y-Y.: Silica/polyimide hybrids and their dielectric properties. I. Preparation with an improved sol-gel process with poly(amic acid) as the precursor. Journal of Applied Polymer Science, 97, 20-24 (2005).

DOI: $10.1002 / a p p .21721$

[47] Chen Y., Iroh Y. O.: Synthesis and characterization of polyimide/silica hybrid composites. Chemistry of Materials, 11, 1218-1222 (1999). DOI: $\underline{10.1021 / \mathrm{cm} 9804281}$

[48] Musto P., Ragosta G., Scarinzi G., Mascia L.: Toughness enhancement of polyimide by in situ generation of silica particles. Polymer, 45, 4265-4274 (2004). DOI: 10.1016/j.polymer.2004.03.099

[49] Xenopoulos C., Mascia L., Shaw S. J.: Variables analysis in the gelation of alkoxysilane solutions for the production of polyimide-silica hybrids. Material Science and Engineering: C, 6, 99-114 (1998). DOI: $\underline{10.1016 / \mathrm{S} 0928-4931(98) 00040-X}$ 
[50] Ragosta G., Musto P., Abbate M., Russo P., Scarinzi G.: Fracture behaviour and deformation mechanisms of polyimide/silica hybrids. Macromolecular Symposia, 228, 287-298 (2005).

DOI: $10.1002 /$ masy.200551026

[51] Karger-Kocsis J., Czigany T., Moskala J.: Thickness dependence of work of fracture parameters of amorphous copolyester. Polymer, 38, 4587-4593 (1997). DOI: $\underline{10.1016 / \mathrm{S} 0032-3861(96) 01061-0}$

[52] Wu S.: A generalized criterion for rubber toughening: The critical matrix ligament thickness. Journal of Applied Polymer Science, 35, 549-561 (1988). DOI: $10.1002 / a p p .1988 .070350220$

[53] Bagheri R., Pearson R. A.: Role of particle cavitation in rubber-toughened epoxies: II. Inter-particle distance. Polymer, 41, 269-276 (2000). DOI: $10.1016 /$ S0032-3861(99)00126-3

[54] Premachandra J., Kumudine C., Mark J. E., Dang T. D., Chen J. P., Arnold F. E.: Polymer-silica hybrid materials prepared from some functionalized polybenzoxazoles and polybenzobisthiazoles. Journal of SolGel Science and Technology, 7, 163-175 (1996). DOI: 10.1007/BF00401035

[55] Kumudinie C., Premachandra J. K., Mark J. E., Dang T. D., Arnold. F. E.: Preparation and properties of some hybrid aerogels from a sulfopolybenzobis thiazole-silica. Journal of Macromolecular Science Part A: Pure Applied Science, 36, 73-83 (1999). DOI: $10.1081 / \mathrm{MA}-100101517$

[56] Suzuki T., Yamada Y.: Physical and gas transport properties of novel hyperbranched polyimide-silica hybrid membranes. Polymer Bulletin, 53, 139-146 (2005).

DOI: $10.1007 / \mathrm{s} 00289-004-0322-9$

[57] Cornelius C., Hibshman C., Marand E.: Hybrid organic-inorganic membranes. Separation and Purification Technology, 25, 181-193 (2001). DOI: $10.1016 / \mathrm{S} 1383-5866(01) 00102-2$

[58] Ree M., Goh W. H., Kim Y.: Thin films of organic polymer composites with inorganic aerogels as dielectric materials: Polymer chain orientation and properties. Polymer Bulletin, 35, 215-222 (1995). DOI: $10.1007 / \mathrm{BF} 00312917$

[59] Mukherjee S. P., Suryanarayana D., Strope D. H.: Solgel processing in electronic packaging materials. Journal of Non-Crystalline Solids, 147-148, 783-791 (1992). DOI: 10.1016/S0022-3093(05)80717-3

[60] Kim Y., Kang E., Kwon Y. S., Cho W. J., Cho C., Chang M., Ree M., Chang T., Ha C. S.: Electrical properties of silica-polyimide composite dielectric thin films prepared via sol-gel reaction and thermal imidization. Synthetic Metals, 85, 1399-1400 (1997). DOI: $10.1016 / \mathrm{S} 0379-6779(97) 80291-3$

[61] Jiang L., Liu J., Wu D., Li H., Jin R.: A methodology for the preparation of nanoporous polyimide films with low doelectric constants. Thin Solid Films, 510, 241-246 (2006).

DOI: $\underline{10.1016 / j . t s f .2005 .12 .216}$
[62] Huang J-C., He C-B., Xiao Y., Mya K. Y., Dai Y., Siow Y. P.: Polyimide/POSS nanocomposites: Interfacial interaction, thermal properties and mechanical properties. Polymer, 44, 4491-4499 (2003). DOI: $10.1016 / \mathrm{S} 0032-3861(03) 00434-8$

[63] Chen Y., Kang E. T.: New approach to nanocomposites of polyimide containing polyhedral oligomerric silsesquioxane for dialectric applications. Materials Letters, 58, 3716-3719 (2004).

DOI: $10.1016 /$ j.matlet.2004.08.001

[64] Nguyen C. V., Carter K. R., Hawker C. I., Hedrick J. L., Jaffer R. L., Miller R. D., Remunar J. F., Rhee H. W., Rice P. M., Toney M. F., Trollsas M., Yoon D. Y.: Low-dielectric, nanoporous organosilcate film prepared via inorganic/organic polymer hybrid templates. Chemistry of Materials, 11, 3080-3085 (1999). DOI: $10.1021 / \mathrm{cm} 990114 \mathrm{~d}$

[65] Wahab M. A., Kim I., Ha C-S.: Microstructure and properties of polyimide/poly(vinylsilsesquioxane hybrid composite films. Polymer, 44, 4705-4713 (2003). DOI: $10.1016 / \mathrm{S} 0032-3861(03) 00429-4$

[66] Qiu F., Xu H., Cao Y., Jiang Y., Zhou Y., Liu J., Zhang X.: Nonlinear optical materials: Synthesis, characterization, thermal stability and electro-optical properties. Materials Characterization, 58, 275-283 (2007). DOI: 10.1016/j.matchar.2006.05.003

[67] Zhu Z-K. U., Yin J., Cao F., Shang X. Y., Lu Q. H.: Photosensitive polyimide /silica hybrids. Advanced Materials, 12, 1055-1057 (2000).

DOI: 10.1002/1521-4095(200007)12:14<1055::AIDADMA1055>3.0.CO;2-\#

[68] Liu L., Lu Q., Yin J., Qian X., Wang W., Zhu Z., Zongguang W.: Photosensitive polyimide (PSPI) materials containing inorganic-nano particles (I)PSPI/TiO 2 hybrid materials by sol-gel process. Materials Chemistry and Physics, 74, 210-213 (2002). DOI: $10.1016 / \mathrm{S} 0254-0584(01) 00456-4$

[69] Wang W-Y., Yen C-T., Chen W-C.: Photosensitive polyimide/silica hybrid optical materials: Synthesis, properties and patterning. Polymer, 46, 6959-6967 (2005).

DOI: 10.1016/j.polymer.2005.06.026

[70] Yu Y-Y., Chien W-C., Lai C-L.: Synthesis and optical properties of photosensitive polyimide/silica hybrid thin films. Materials Chemistry and Physics, 113, 567-573 (2009).

DOI: $10.1016 /$ j.matchemphys.2008.08.012

[71] Zhong S-H., Li C-F., Xiao X-F.: Preparation and characterization of polyimide-silica hybrid membranes on kieselguhr-mullite supports. Journal of Membrane Science, 199, 53-58 (2002). DOI: $10.1016 / \mathrm{S} 0376-7388(01) 00676-7$ 
[72] Hu Q., Marand E., Dhingra S., Fritsch D., Wen J., Wilkes G.: Poly(amide-imide)/TiO 2 nano-composite gas separation membranes: Fabrication and characterization. Journal of Membrane Science, 135, 65-79 (1997).

DOI: $10.1016 / \mathrm{S} 0376-7388(97) 00120-8$

[73] Joly C., Goizet S., Schrotter J. C., Sanchez J., Escoubes M.: Sol-gel polyimide-silica composite membrane: Gas transport properties. Journal of Membrane Science, 130, 63-74 (1997). DOI: $\underline{10.1016 / \mathrm{S} 0376-7388(97) 00008-2}$

[74] Joly C., Smaihi M., Porcar L., Noble R. D.: Polyimide-silica composite materials: How does silica influence their microstructure and gas permeation properties? Chemistry of Materials, 11, 2331-2338, (1999).

DOI: $\underline{10.1021 / \mathrm{cm} 9805018}$

[75] Hu Q., Marand E., Dhingra S., Fritsch D., Wen D., Wilkes G. L.: Ply(amide-imide) $/ \mathrm{TiO}_{2}$ nano-composite gas separation membranes: Fabrication and characterization. Journal of Membrane Science, 135, 65-79 (1997).

DOI: $10.1016 / \mathrm{S} 0376-7388(97) 00120-8$
[76] Cornelius C. J., Marand E.: Hybridsilica-polyimide composite membranes: Gas transport properties. Journal of Membrane Science, 202, 97-118 (2002). DOI: $10.1016 / \mathrm{S} 0376-7388(01) 00734-7$

[77] Musto P., Mascia L., Mensitieri G., Ragosta G.: Diffusion of water and ammonia through polyimide-silica bicontinuous nanocomposites: Interactions and reactions. Polymer, 46, 4492-4503 (2005).

DOI: $10.1016 /$ j.polymer.2005.02.032

[78] Musto P., Ragosta G., Scarinzi G., Mensitieri G.: Spectroscopic studies of the diffusion of water and ammonia in polyimide and polyimide-silica hybrids. in 'New polymeric materials' (eds.: Korugic-Karasz L. S.,. MacKnight W. J., Martuscelli E.) ACS Simposium Series, Washington, Vol 916, 296-308 (2005).

[79] Musto P., Ragosta G., Scarinzi G., Mascia L.: Structure-properties correlation in polyimide/silica hybrids. High Performance Polymers, 18, 799-816 (2006). DOI: $\underline{10.1177 / 0954008306068257}$

[80] Musto P., Ragosta G., Mensitieri G., Lavorgna M.: On the molecular mechanism of $\mathrm{H}_{2} \mathrm{O}$ diffusion into polyimides: A vibrational spectroscopy investigation. Macromolecules, 40, 9614-9627 (2007). DOI: $\underline{10.1021 / \mathrm{ma} 071385+}$ 